\title{
Knowledge, Attitude and Practice regarding smoking among medical students
}

\author{
Rizwan Ahmad S. ${ }^{1 *}$, Abdul Thaher M. ${ }^{2}$, Chandrasekhar A. ${ }^{3}$ \\ DOI: https://doi.org/10.17511/ijphr.2016.i3.02 \\ 1* Sultan Rizwan Ahmad, Associate Professor, Deartment of Community Medicine, Deccan College of Medical Sciences, Hyderabad, \\ Telangana, India. \\ 2 Mohammad Abdul Thaher, Post Graduate Resident, Department of Community Medicine, Deccan College of Medical Sciences, Hyderabad, \\ Telangana, India. \\ 3 Addepalli Chandrasekhar, Professor, Department of Community Medicine, Deccan College of Medical Sciences, Hyderabad, Telangana, \\ India.
}

Background: Tobacco smoking is a risk factor for many disease and cancers and one of the leading causes of death. Smoking is rampant among medical students all over the world. This study has been aimed at studying the knowledge, attitude and practice regarding smoking and awareness of smoking related legislation among medical students. Materials and Methods: A cross sectional study was carried out among the medical students in a Medical college. All students given consent were interviewed using a pre-designed and pretested questionnaire at a convenient time. Study and confidentiality aspects were explained to the students. Data were collected regarding knowledge, attitude and practice of smoking. Results: Prevalence of smoking was $18 \%$ among male students and nil among female students. Mean age of starting smoking was 18 years. $68 \%$ were daily smoker, and smoke 10 or fewer cigarettes daily. 44\% got influenced by friends in initiating smoking. $63 \%$ smoker have smoker in friends or family. $36 \%$ of smokers have habit of alcohol consumption associated with smoking. $32 \%$ did not aware of legislation related to smoking. $20 \%$ students are aware that smoking is banned in educational institution. Conclusion: Students are trying to quite the smoking, support from friends and family could contribute significantly in helping them. Awareness regarding legislation related to smoking should be incorporated in students counseling activities.

Keywords: Smoking, Medical students, Legislation, Alcoholism

Corresponding Author

Sultan Rizwan Ahmad, Associate Professor, Deartment of Community Medicine, Deccan College of Medical Sciences, Hyderabad, Telangana, India. Email: mysultan77@yahoo.com

\section{How to Cite this Article}

Ahmad SR, Thaher MA, Chandrasekhar A. Knowledge, Attitude and Practice regarding smoking among medical students. Public Health Rev Int J Public Health Res. 2016;3(3):96-101. Available From https://publichealth.medresearch.in/index.php/ijphr/ article/view/38
To Browse

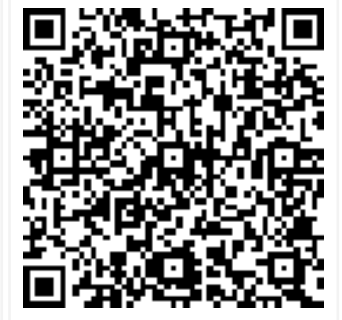

Manuscript Received 2016-04-10

Conflict of Interest No

Review Round 1
2016-04-24
Funding
Nil
(c) 2016 by Sultan Rizwan Ahmad, Mohammad Abdul Thaher, Addepalli Chandrasekhar and Published by Siddharth Health
Research and Social Welfare Society. This is an Open Access article licensed under a Creative Commons Attribution 4.0 International License https://creativecommons.org/licenses/by/4.0/ unported [CC BY 4.0].

Accepted 2016-05-22

Note 


\section{Introduction}

Tobacco kills 1 person every 6 seconds [1]111111 but it rarely makes headlines. Smoking is a risk factor for 6 leading causes of death [2]. Richard peto in his study in 1994 found that average loss of life for all cigeratte smoker was about 8 years and for those who died were 16 years [3]. A 3 inch cigarette can lessen your life by 3 minute. Smoking statistics according to WHO indicate more than a billion smokers till May 2010 [4].

Among one billion Indians, about 300 million adults use tobacco in various forms ( $47 \%$ of men and $14 \%$ of women use tobacco in India). Each year nearly one million people die of tobacco related morbidity in India and thousands of million exchequers is wasted [5]. According to WHO, mortality statistics have predicted a 10 fold rise in 21st century compared to 100 million lives lost to smoking in the previous century. Tax increase by $10 \%$ worldwide can prevent a minimum of 10 million tobacco related deaths [2].

In spite of this, we have not succeeded in rendering effective precautionary measures against smoking. Tobacco companies have long targeted youth as "replacement smokers" to take succeed those who quit or die. The industry knows that addicting youth is its future. Although anyone who uses tobacco can become addicted to nicotine, people who do not start smoking before age 21 are unlikely to ever begin [6].

Smoking is rampant among medical students all over the world. Without proficient preventive measures the numbers are steadily rising in countries like India. In a study across 15 medical colleges lifetime prevalence of cigarette smoking in medical students was reported to be $28.2 \%$. Over one fourth $(27.2 \%)$ of medical students initiated daily cigarette smoking before age 15 [4].

The ever demanding medical curriculum along with increasing career competition contributes to anxiety making medical students vulnerable to smoking. However medical students as future healthcare providers have to be torchbearers of a healthy lifestyle. Ideally they have to practice what they preach. In 2003, India passed an act banning smoking in public places.

The ministry of health and family welfare is now focusing on measures to ensure effective implementation and enforcement of this act.
This study has been aimed at studying the knowledge, attitude and practice regarding smoking and awareness of smoking related legislation among medical students.

\section{Materials and Methods}

A cross sectional study was carried out among the medical students in Deccan college of Medical Sciences from August 20015 to October 20015 for a period of 3 month. Students spanning the entire M.B.B.S course and consenting to participate in the study were included as study population. Newly joined first year students were not included in study as they were just one month old in medical college at the time of study.

Study was approved by ethical committee of institute. All students given consent were interviewed using a pre-designed and pretested questionnaire at a convenient time. Study and confidentiality aspects were explained to the students. Data were collected regarding knowledge, attitude and practice of smoking. Data were entered in excel and analyzed by SPSS version 11 and graph pad.

\section{Results}

Total 404 students participated in study 138 were male and 266 were female. Mean age of male participants was $20.2(S D=1.66)$ and female 20.09 $(S D=1.71)$. All 25 smoker were male while among female there were no smoker (table 1). Mean age of starting smoking was 18 years $(S D=2.69)$. 1 smoker was in 3rd semester, 6 in 5th semester, 7 in 7th semester and 11 were in 9 th semester.

$68 \%$ were daily smoker, $12 \%$ occasionally smoker. (table 2). $68 \%$ smoke 10 or less cigarette daily, $24 \%$ smoke 11-20 cigarette daily, and $8 \%$ smoke more then 30 cigarette daily.(table 3 ). $44 \%$ got influenced by friends in initiating smoking, $16 \%$ by stress of studies and $20 \%$ by movies and others (table 4 ). $56 \%$ of smoker said they smoke for relaxing effect, and $24 \%$ smoke for better concentration.(table 5). $32 \%$ smoker refrain smoking in forbidden places while $60 \%$ do not refrain and $8 \%$ did not responded to the question. $36 \%$ of smoker have habit of alcohol consumption associated with smoking.

$31 \%$ drugs and $20 \%$ pan, tobacco and gutkha consumption.(table 6). 95\% smoker tried to quite the smoking. $63 \%$ smoker have smoker in friends or family. 
$85 \%$ smokers don't mind smoking while $15 \%$ mind it. $88 \%$ smoker said they will advise smoker to quit it. $68 \%$ students are aware of legislation related to smoking while $32 \%$ did not aware of it.

$20 \%$ students are aware that smoking is banned in educational institution, $15 \%$ aware that it is banned in cinema hall, $14 \%$ aware that it is banned at bus stops and railway stations, $15 \%$ aware that it is banned in public transport and only $31 \%$ aware that smoking is banned at all of these sites.(table7)

Table-1: Smoking status of medical students $(n=404)$

\begin{tabular}{|l|l|l|l|l|}
\hline Smoking status & Males & Percentage & Females & Percentage \\
\hline Smoker & 25 & $18.11 \%$ & 0 & $0 \%$ \\
\hline Non Smoker & 113 & $81.89 \%$ & 266 & $100 \%$ \\
\hline Total & 138 & $100 \%$ & 266 & $100 \%$ \\
\hline
\end{tabular}

Table-2: Distribution of medical students according to frequency of smoking $(n=25)$

\begin{tabular}{|l|l|l|}
\hline \multicolumn{1}{|c|}{ Frequency among smokers } & Responses & Percentage \\
\hline Daily & 17 & $68 \%$ \\
\hline Occasionally & 3 & $12 \%$ \\
\hline Non response & 5 & $20 \%$ \\
\hline Total & 25 & $100 \%$ \\
\hline
\end{tabular}

Table-3: Distribution of smokers according no of cigarettes smoked $(\mathbf{n}=\mathbf{2 5})$

\begin{tabular}{|l|l|l|}
\hline \multicolumn{1}{|c|}{ No of cigarettes smoked } & Responses & Percentage \\
\hline 10 or less & 17 & $68 \%$ \\
\hline $11-20$ & 6 & $24 \%$ \\
\hline $21-30$ & 0 & $0 \%$ \\
\hline$>30$ & 2 & $8 \%$ \\
\hline
\end{tabular}

Table-4: Distribution of smokers according to influence in initiating smoking $(n=25)$

\begin{tabular}{|l|l|l|}
\hline \multicolumn{1}{|c|}{ Reasons } & Responses & Percentage \\
\hline Influence of friends & 11 & $44 \%$ \\
\hline Influence of others (like movie stars etc & 3 & $12 \%$ \\
\hline Stress of studies & 4 & $16 \%$ \\
\hline others & 2 & $8 \%$ \\
\hline No response & 4 & $16 \%$ \\
\hline Total & 25 & $100 \%$ \\
\hline
\end{tabular}

Table-5: Distribution of smokers according to reasons for smoking $(n=25)$

\begin{tabular}{|l|l|l|}
\hline \multicolumn{1}{|c|}{ Reason for smoking } & Responses & \multicolumn{1}{c|}{ Percentage } \\
\hline For relaxing effect & 14 & $56 \%$ \\
\hline For better concentration & 6 & $24 \%$ \\
\hline Other & 4 & $16 \%$ \\
\hline No response & 1 & $4 \%$ \\
\hline Total & 25 & $100 \%$ \\
\hline
\end{tabular}

Table- 6: Distribution of smokers according to habits associated with smoking $(\mathbf{n = 2 5})$

\begin{tabular}{|l|l|}
\hline \multicolumn{2}{|c|}{ Habits associated with smoking } \\
\hline Alcohol & $36.84 \%$ \\
\hline Drugs & $31.57 \%$ \\
\hline Pan chewing & $10.52 \%$ \\
\hline Tobacco chewing & $5.26 \%$ \\
\hline Ghutka & $5.26 \%$ \\
\hline
\end{tabular}

Table-7: Awareness of places where smoking is banned $(n=404)$

\begin{tabular}{|l|l|}
\hline \multicolumn{1}{|c|}{ Banned places } & \\
\hline$(1=$ Educational institutions $)$ & $20.63 \%$ \\
\hline$(2=$ Cinema halls $)$ & $15.21 \%$ \\
\hline$(3=$ Bus stops \& Railway stations $)$ & $14.30 \%$ \\
\hline$(4=$ Public transports $)$ & $15.81 \%$ \\
\hline$(5=$ Pubs and bars $)$ & $1.35 \%$ \\
\hline $6=$ All of the above $)$ & $31.62 \%$ \\
\hline (7= None of the above $)$ & $1.05 \%$ \\
\hline
\end{tabular}

\section{Discussion}

The aim of this study was to study the knowledge, attitude and practice regarding smoking and awareness of smoking related legislation among medical students. There were 25 smokers (18\%) among male students only while all female were non smoker, mean age of starting smoking was 18 years. Sailesh Mohan et al in a study in Kerala, India came out with results of prevalence of smoking as $14.1 \%$ in medical students [7].

Ranjeeta Kumari in her study on the" Use of Tobacco Among Male Medical Students in Lucknow" came out with reports of smokers constituting $25.2 \%$ [8]. Zhouei et al in a study shows that the smoking rate among Shanghai medical students was $21.42 \%$ for male student [9]. In a study by Khuder SA, $61 \%$ smokers started smoking before 18 years of age [6]. Age at initiation of smoking is a significant factor for continuation and heavy smoking.

Men who started smoking before 16 years of age has two times risk of not quitting smoking compare to those who started at a later age. The relationship between young age at starting and high number of cigarettes smoked per day further stresses the importance of age at starting smoking on subsequent health consequences [10]. In this study $68 \%$ were daily smoker. In a Turkish study daily smoking rates among males were found to range from 35.0 to $56.9 \%$ [11]. 
Our study found that $44 \%$ got influenced by friends in initiating smoking, $16 \%$ by stress of studies and $20 \%$ by movies and others. Ranjeeta Kumari in her study revealed that tobacco use is mostly initiated due to peer pressure (78\%). The other important factors responsible were curiosity and the effect of family members [8]. In this study $56 \%$ of smoker said they smoke for relaxing effect. Medical

Students having strenuous schedules and burdened with their academics are more likely to be overstressed. The response of more than half of participants answering the reason for continuing smoking as to relax is evident here. This study shows us that alcohol accounted most for adverse habits associated with smoking but drugs were equally used by medical students. This indicates the vulnerability of medical students to these habits.

In this study $95 \%$ smokers tried to quite the smoking. Kerala study [7] found that only $16 \%$ of medical students had attempted to quit while Turkish study [11] found that $22.4 \%$ of medical students who smoke were not interested in quitting. This study found that $1 / 3$ rd students are not aware of legislation related to smoking. Almost of all the students who were smokers tried to quit smoking. This shows the willingness of the smokers to quit and also their failure in cessation of smoking.

\section{Conclusion}

Students are trying to quite the smoking, support from friends and family could contribute significantly in helping them. Awareness regarding legislation related to smoking should be incorporated in students counseling activities. These findings emphasize the need for prevention programme targeted to young age. Handing over an addiction free society in inheritance to later generations is the need of the hour and urgent efforts should be aimed towards prevention of smoking.

\section{Reference}

01. Mathers CD, Loncar D. Projections of global mortality and burden of diseases from 2002 to 2030. PLOS medicine. 2006;3(11)e442.

Available from: [Article] [Crossref]

02. MPOWER. A WHO report on tobacco endemic. 2008.

Available from: [Article] [Crossref]
03. Peto $R$, et al. Mortality from smoking worldwide. British medical Bulletin. 1996;52(1)12-21. [Crossref]

04. Statistics from world tobacco day. Available from: [Article] [Crossref]

05. A report on India Global Health Professionals 2006 by Ministry of Health and Family Welfare. Government of India, New Delhi World Health Organization India Office, New Delhi. pg-5. [Crossref]

06. Khuder SA, Dayal, mulgi AB. Age of smoking onset and its effect on smoking cessation. Addictive behavior. 1991;24(5)673-677. [Crossref]

07. Mohan S, et al. Tobacco use among medical professionals in Kerala, India- The need for enhanced tobacco cessation and control efforts. Science direct Addictive Behavoirs. 2006;31(12)2313-18.

[Crossref]

08. Kumari R, Nath B. Study on the Use of Tobacco Among Male Medical Students in Lucknow. Indian Journal of Community Medicine. 2008 Apr;33(2)100-103.

[Crossref]

09. Zhou lei, Huang jingheng, Liu jianzhong. Smoking among shanghai medical students and the need for comprehensive intervention strategies. Health Promotion International. $1997 ; 12(1) 27-31$.

[Crossref]

10. Barbara D Avanzo, Carlo La Vecchia, Eva Negri. Age at starting smoking and number of cigarettes smoked. Annals of epidemiology. 1994;4(6)455-459.

[Crossref]

11. Cooper $\mathrm{R}$, et al. Smoking habits of medical school students in Turkey- Has anything changed. Turkish Journal of Cancer. $2004 ; 34(4) 146-149$.

[Crossref] 